meals can be minimized by the use of that insulin or combination of insulins best suited to the patient. In our experience nearly all of the so-called difficult diabetics can be satisfactorily controlled by soluble insulin and protamine zinc insulin in the morning and soluble insulin in the evening, provided they understand and put into practice the principles of diabetic self-regulation (Dunlop and Duncan, 1964). In some patients this proves impossible for several reasons, of which two are mentioned above; although these could have been overcome by using other insulins-for example, soluble and globin insulins given twice daily-the crystal insulins seemed to be suitable and had the advantage of being miscible in the same syringe.

The results show that in these circumstances the insulins were satisfactory and that the major action of each insulin was correctly reflected by the selected urine test on which its dosage was based. The dose of Actrapid, however, was usually much less than that of Crystal II insulin because of the overlapping effect of the previously injected Crystal II. Nevertheless the patients readily appreciated that during each of the four periods of the day (morning, afternoon, evening, and night) one insulin was having its greatest effect, and had no difficulty in making the necessary adjustments in dosage or diet to allow for flexibility in their physical activity and meals. This regime would seem to be suitable for the limited number of diabetics who are not well controlled on more conventional insulin regimes.

A mixture of Actrapid and Crystal II insulins is now available as Rapitard (Lopez and Colombo, 1964 ; Schlichtkrull et al.,
1965). This mixing of the two insulins in predetermined proportions is in our view most regrettable, since it deprives them of their only advantage, which is the appropriate adjustment of their individual dosage by the patient.

\section{Summary}

Time-action studies of Actrapid and Crystal II insulins are reported. Actrapid insulin has a short action comparable to soluble insulin, and Crystal II insulin has an intermediate time-action.

The method and results of their use over a period of one to two years are described in a group of 10 patients whose control was previously judged as unsatisfactory.

We are indebted to Drs. K. Hallas-Moller and J. Schlichtkrull, of the Novo Terapeutisk Laboratories, Copenhagen, and to Dr. G. A. Carnachan, of Evans Medical Ltd., Liverpool, for generous supplies of Actrapid and Crystal II insulins; to Professor L. G. Whitby, of the Department of Clinical Chemistry, for the bloodglucose estimations ; and to Miss $\mathrm{O}$. Jehu, dietitian, and the nursing staff for valuable assistance with the time-action studies.

\section{REFERENCES}

Dunlop, Sir Derrick, and Duncan, L. J. P. (1964). In Textbook of Medical Treatment, edited by Sir Derrick Dunlop, Sir Stanley Davidson, and S. Alstead, 9th ed., pp. 341-357. Livingstone, Edinburgh. Lopez, V., and Colombo, J. P. (1964). Schweiz. med.' Wschr., 94, 788. Schlichtkrull, J., Munck, O., and Jersild, M. (1965). Acta med. scand., 177, 103 .

\title{
An Improved Method of Transporting Donor Eyes
}

\author{
F. O. MUELLER,* M.D., D.O. ; P. O'NEILL,* B.SC. ; P. D. TREVOR-ROPER,* M.D., F.R.C.s., D.o.M.s.
}

Brit. med. F., 1965, 2, 267-270

In 1922 Filatov reported that corneas from cadavers formed satisfactory homografts. It has since been shown that for a successful graft of the full corneal thickness the donor eye should be removed within 10 to 15 hours after death, and should be stored for not longer than three days (Rycroft, 1962).

The establishment of the Westminster-Moorfields Eye Bank has allowed a reassessment of some of the methods devised for short-term storage and transport of these donor eyes. In this paper we present some of our findings and describe new equipment for the transport of eyes.

\section{Materials and Methods}

After preliminary trials with various transport-containers we chose a metal box (known as " box A"), which appears to be that in most general use in England, and which represents the prototype of other transport-containers available. This was used as a basis for comparison with " box B," made of foamed polystyrene, which we have designed in an attempt to find a container that is more economical, lighter in weight, and, in particular, one that achieved better temperature-control.

Box A (Fig. 1) consists essentially of two metal boxes, one within the other, the intervening space being filled with fibreglass. Two specimen jars are fixed in the centre of the container by a screw-clamp, and ice is packed around them. The \footnotetext{
* From the Department of Ophthalmology, Westminster Hospital,
London.
}

metal lid, of a similar structure as the container, is rubber-lined, and is clamped down on the container to make it watertight. The dimensions of the box are 9 in. $\left(22.8 \mathrm{~cm}\right.$.) long, $6 \frac{1}{2} \mathrm{in}$. $(16.5 \mathrm{~cm}$.) wide, 6 in. $(15.2 \mathrm{~cm}$.) high; its weight is $3.3 \mathrm{~kg}$. when empty; and the volume of the ice compartment is 1.37 litres.

Box B (Fig. 2) is made of foamed polystyrene. A large central cavity holds the ice in a plastic bag, and communicates

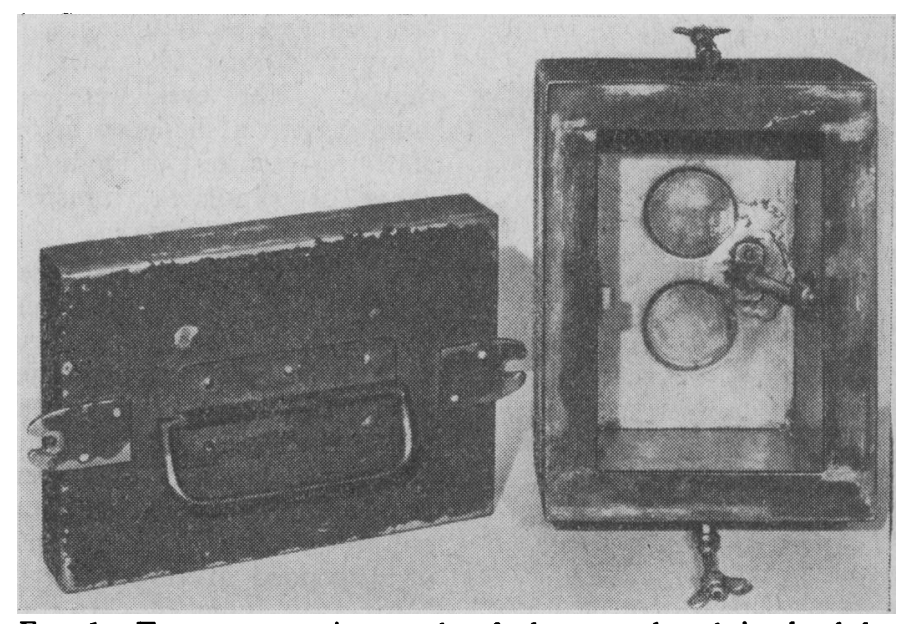

Fig. 1.- Transport container made of sheet metal and insulated by fibreglass-box A. 
with four smaller cavities in which the specimen jars sit firmly without any need for further fixation. The lid, which is of the same material, is strapped tightly in place with adhesive tape. The dimensions of the box are $10 \mathrm{in}$. $(25.4 \mathrm{~cm}$.) long, $8 \mathrm{in}$. $\left(20.3 \mathrm{~cm}\right.$.) wide, $8 \frac{3}{4} \mathrm{in}$. (22.2) high ; its weight is $0.24 \mathrm{~kg}$.; and the volume of the ice compartment is 1.12 litres.

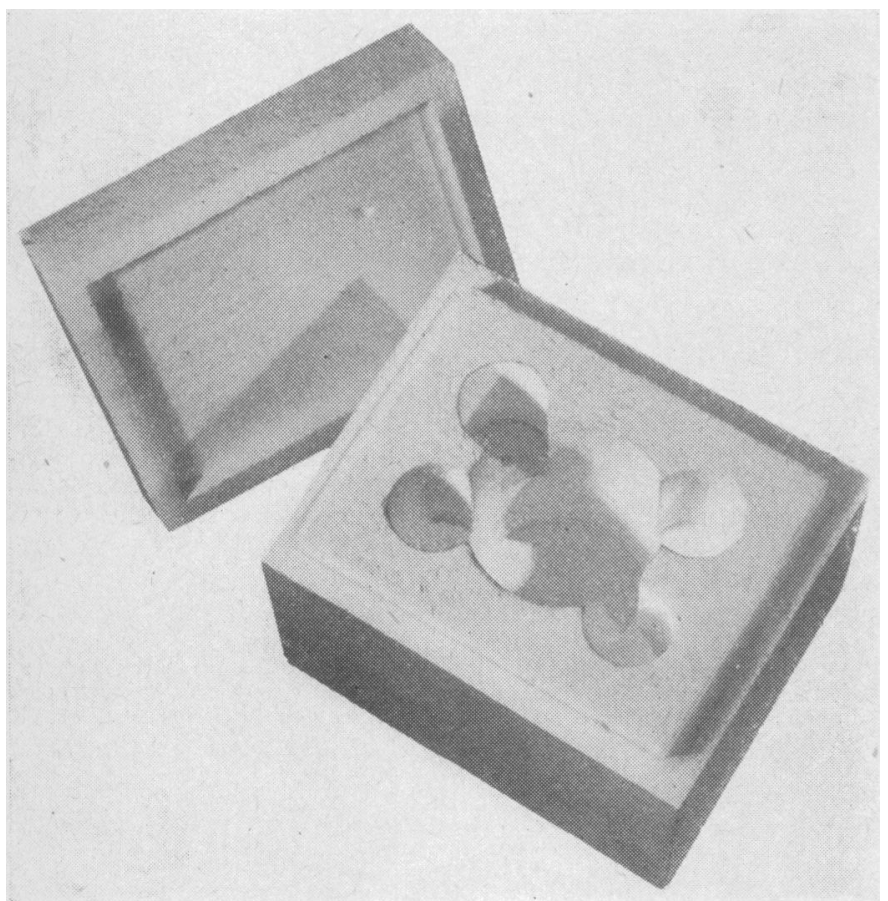

FIG. 2.-Transport container made of foamed polystyrene-box B.

An electric thermometer recorded the temperatures in the anterior chambers of the eyes in the specimen jars, as well as the temperatures of the ice in the boxes $\mathrm{A}$ and $\mathrm{B}$, and of the external air. Copper constantan thermocouples incorporated in the tips of hypodermic needles were used, and the temperatures read directly. The range of the thermometer was $-4^{\circ} \mathrm{C}$. to $+50^{\circ} \mathrm{C}$., the scale being graduated in $0.2^{\circ} \mathrm{C}$.

Varying conditions that might occur during the transport of donor eyes were imitated. An incubator provided different external temperatures, and ice cubes from domestic refrigerators

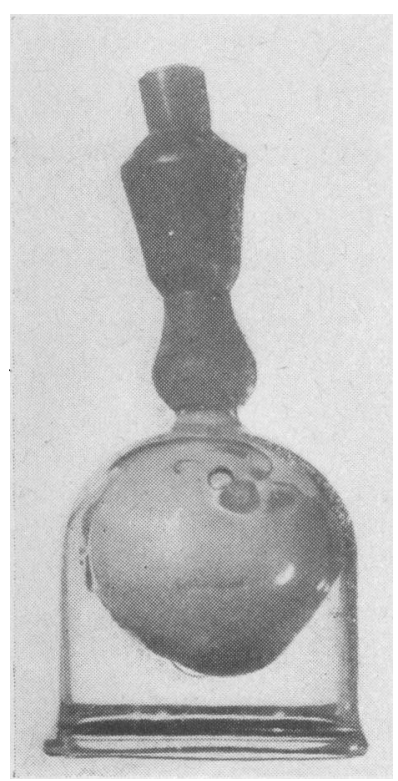

FIG. 3.-Donor eye suspended in glass bell and held in position by negative pressure. were used to determine the effect of ice at different temperatures and of varying sizes. The effect of movement during transport was simulated by a laboratory shaker to which the boxes $A$ and $B$ were secured and agitated at frequencies of between 140 and 180 times per minute. The eyes were examined with a slit-lamp before and after each test to study the effect of simulated transport under varying conditions.

In the experiments we used human donor eyes which were unsuitable for corneal grafting, as well as eyes from cadaver dogs. In some of these experiments they were placed in dry jars, and in others they were immersed in Parker 199 tissueculture medium, either loosely or suspended in glass bells.

The glass bell (supplied by John Weiss and Son, London) is used to prevent mechanical damage to the cornea, and is shown in Fig. 3. A self-sealing latex rubber cap (obtained from Baxter Laboratories Ltd.) is fitted over the outside of the hollow stem of the glass bell. The donor eye is placed with its optic nerve over the internal opening of the hollow stem; a hypodermic needle pierces through the latex rubber cap, and, with the attached $20-\mathrm{ml}$. syringe, air is withdrawn so that the optic nerve is sucked up into the hollow stem. After removing the hypodermic needle the negative pressure holds the eyeball in position with its posterior pole adhering to the glass bell by suction. The glass bell is then placed in the specimen jar and the lid screwed on. The lid presses down the protruding latex rubber cap and thus holds the glass bell so securely in place within the specimen jar that no movements can disturb the glass bell or the eye (Fig. 4).

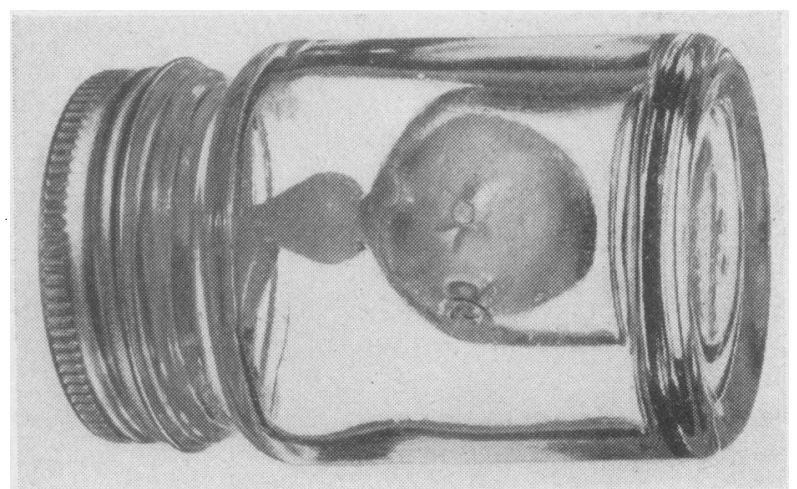

FIG. 4.-Donor eye in glass bell placed in specimen jar (allowing firm fixation of eye and bell).

\section{Results}

\section{Donor Eyes Kept in Ice at One Temperature $\left(-0.5^{\circ}\right.$ C. $)$ in Containers Exposed to Three Different External Temperatures}

The effective storage time of a container may be defined as the maximum period of time during which the stored eyes maintain a steady temperature with a variation of not more than $2^{\circ} \mathrm{C}$.

In 12 experiments the effective storage time of box $\mathrm{A}$ was found to differ greatly from that of box B. With box $A$ it was very much dependent upon the external temperatures. At an external temperature of $+10^{\circ} \mathrm{C}$. the stored eyes maintained a steady temperature for an average of 16 hours; at $+20^{\circ} \mathrm{C}$. for only five hours; and at $+30^{\circ} \mathrm{C}$. for less than three hours. On the other hand, the stored eyes in box B maintained a steady temperature, when the external temperature was at $+10^{\circ} \mathrm{C}$., for over 90 hours; at $+20^{\circ} \mathrm{C}$. for 50 hours; and at $+30^{\circ} \mathrm{C}$. for 44 hours. This represents an effective storage time for box B of approximately seven times that for box A (Fig. 5).

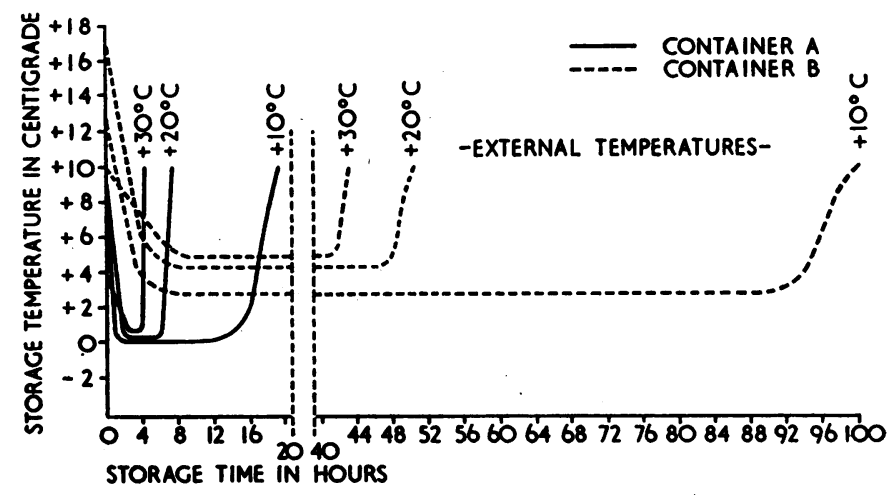

FIG. 5.-Storage time and storage temperature of eyes kept in boxes $A$ and $B$, surrounded by ice at $-0.5^{\circ} \mathrm{C}$. and exposed to three different outside temperatures, with continuous agitation. 
The optimum storage temperatures for tissues is recognized to be between $+2^{\circ} \mathrm{C}$. and $+8^{\circ} \mathrm{C}$. The storage temperatures of eyes kept in box A were recorded much below the desired optimum-they were, in fact, below $1^{\circ} \mathrm{C}$. The storage temperatures of eyes kept in box $\mathrm{B}$, however, were maintained within the optimum-in fact, between $+2.6^{\circ} \mathrm{C}$. and $+6^{\circ} \mathrm{C}$.

\section{Donor Eyes Stored in Ice at Different Initial Temperatures but with Containers Kept at One External Temperature $\left(+20^{\circ}\right.$ C. $)$}

The 20 experiments in this group showed that the temperatures of the eyes in box $A$ were dependent on the ice temperatures, but the temperatures of the eyes in box B were practically independent of the ice temperatures (Fig. 6).

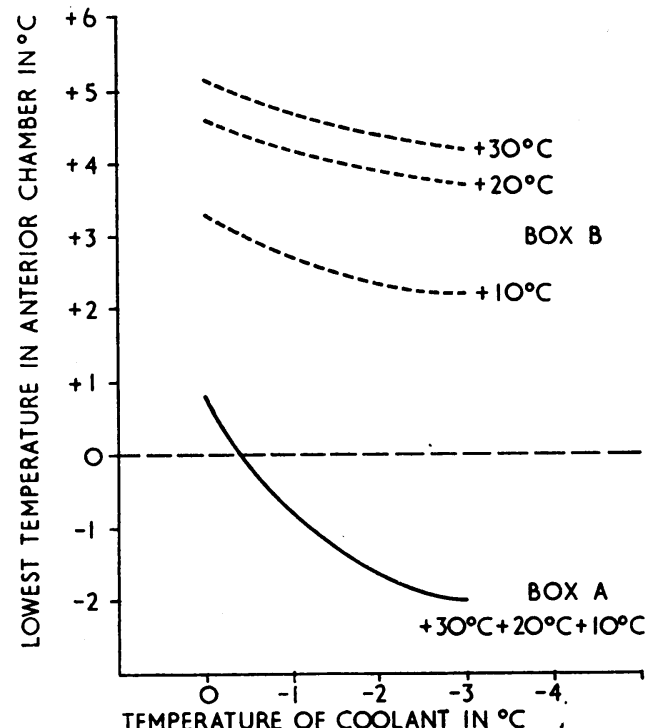

FIG. 6.- Lowest temperature in anterior chambers of eyes in boxes $A$ and $B$ surrounded by ice at different initial temperatures. One curve for box A and three curves for box $\mathrm{B}$ at external temperatures of $+10^{\circ}$ C., $+20^{\circ}$ C., and $+30^{\circ} \mathrm{C}$.

The eyes in box A, surrounded by ice at $-0.2^{\circ} \mathrm{C}$., reached the lowest temperature of $+0.9^{\circ} \mathrm{C}$. ; stored in ice at $-1^{\circ} \mathrm{C}$. they recorded $-0.6^{\circ} \mathrm{C}$; ; and in ice at $-2^{\circ} \mathrm{C}$. the temperature fell to $-1.6^{\circ} \mathrm{C}$. On the other hand, the eyes in box $\mathrm{B}$, stored in ice at the above temperatures $\left(-0.2^{\circ} \mathrm{C} .,-1^{\circ} \mathrm{C}\right.$., $-2^{\circ} \mathrm{C}$. $)$, recorded the lowest temperatures of $+4.7^{\circ} \mathrm{C} .,+4.2^{\circ} \mathrm{C}$., and $+4^{\circ} \mathrm{C}$. respectively. Box A maintained the lowest temperatures for periods up to four hours during the entire storage time, though the length of the storage time was not influenced by the ice temperatures. The storage temperatures, however, varied with the ice temperatures; they were between $-1.6^{\circ} \mathrm{C}$. and $+0.9^{\circ}$ C., and therefore below the optimum storage temperatures.

Box B maintained the lowest temperatures for periods up to 40 hours, and again the lengths of the storage time were not appreciably influenced by the ice temperatures. The storage temperatures were always between $+4^{\circ} \mathrm{C}$. and $+5^{\circ} \mathrm{C}$.

\section{Donor Eyes Stored in Ice at Different Initial Temperatures and Containers Kept at Different External Temperatures}

The tests demonstrated further advantages of box $B$ over box $\mathrm{A}$. The eyes in box $\mathrm{A}$ did not alter the lowest temperatures, but kept them for very short periods of time at $+30^{\circ} \mathrm{C}$., or for almost the entire storage period at $+10^{\circ} \mathrm{C}$.

The lowest temperature of the eyes in box $\mathrm{B}$ is dependent on the ice temperature and on the temperature of the insulation, and therefore different temperature curves exist for various external temperatures and ice temperatures (Fig. 6). When testing extreme temperatures, such as ice at $-2^{\circ} \mathrm{C}$., with an external temperature of $+10^{\circ} \mathrm{C}$., temperatures not lower than $+2.5^{\circ} \mathrm{C}$. were recorded for three-quarters of the storage time ; or when examining high temperatures, such as ice at $-0.2^{\circ} \mathrm{C}$. with an external temperature of $+30^{\circ} \mathrm{C}$., the lowest temperature of $+5^{\circ} \mathrm{C}$. was recorded and maintained for half the storage time.

Initial eye temperatures, measured before the beginning of the experiments, had, for practical purposes, no effect either on the length of storage time or on the lowest or mean storage temperatures. As expected, the rate of fall of temperature increased with higher original eye temperatures and lower ice temperatures.

\section{Eye Temperatures During Rest and Agitation Simulating Transport of Containers}

The temperature curves for the eyes in the boxes, when undisturbed and continuously agitated, were smooth, though they differed in shape (Fig. 7). The curves for the boxes at rest had a semicircular appearance, the slow initial fall passing almost continuously into the gradual rise. Continuous agitation increased the initial cooling rate as well as the rate of rise of final temperature, producing a steep initial descent and a sharp ascent and giving the curves an angular shape. The rate of fall and rise of temperature of the eyes in box A was found to be four to six times as rapid as that with box B. With agitation at intervals the curves ceased to be smooth and showed irregular fluctuations up to $2^{\circ} \mathrm{C}$. in box $\mathrm{A}$ and up to $0.5^{\circ} \mathrm{C}$. in box $\mathrm{B}$. Eyes placed loosely in dry jars, or immersed in fluid, or suspended in glass bells in fluid, all recorded higher rates of temperature fall and rise than those suspended in glass bells and kept in dry jars. Eyes suspended in dry jars reached the lowest temperatures later and held them for shorter periods.

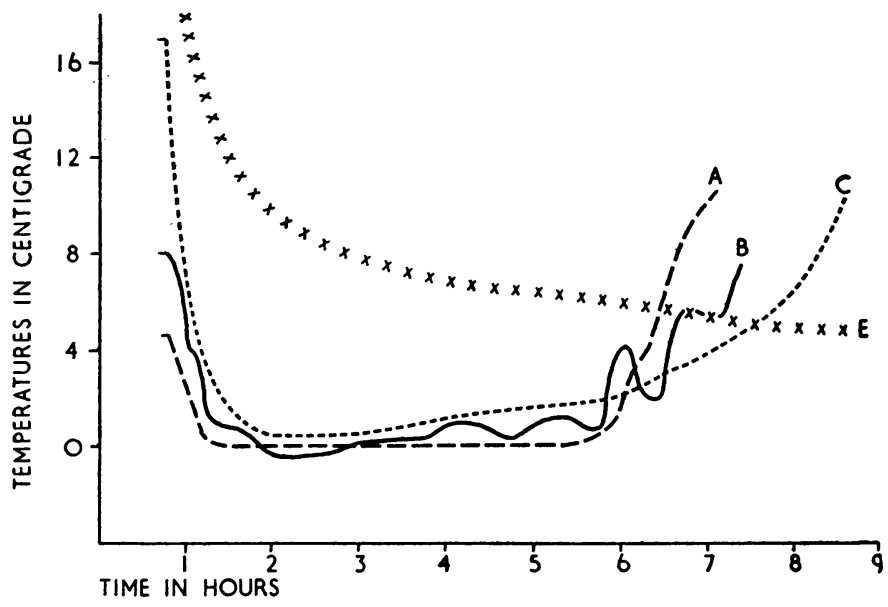

Fig. 7.-Cooling curves of box $\mathbf{A}: \mathbf{A}--$ continuous agitation. Ice temperature at $-0.5^{\circ} \mathrm{C}$. $\mathrm{B}-$ intermittent agitation. Ice temperature at $-0.8^{\circ} \mathrm{C}$. $\mathrm{C}-\mathrm{C}_{-}-\mathrm{undisturbed}^{\circ}$ Ice temperature $-0.2^{\circ} \mathrm{C}$. Cooling curve of box B: $\mathrm{E} \times \mathbf{x} \times \times \times$ undisturbed. Ice temperature

\section{Appearance of Eyes after Storage and Transport in Containers}

The corneas of the eyes which had been kept loosely in specimen jars showed changes visible to the naked eye. Slitlamp examination revealed extensive epithelial defects and localized or diffuse stromal oedema. The globes were soft and the anterior chambers shallow or absent. The changes were particularly noticeable in eyes which had been agitated continuously for four hours, or stored for periods up to 48 hours and agitated for short bouts at long intervals.

Eyes hanging in glass bells and immersed in Parker 199 tissue-culture medium appeared unchanged to the unaided eye 
but only slit-lamp examination revealed a slight increase in stromal thickness. The corneas remained translucent and the pigment floating in the anterior chambers became visible.

In spite of agitation of the containers for periods up to 10 hours the eyes remained suspended in their glass bells, and the iris diaphragm and anterior lens surface did not come in contact with the corneal endothelium.

\section{Conclusions}

Temperatures between $-2^{\circ} \mathrm{C}$. and $+8^{\circ} \mathrm{C}$. are recommended for the storage of red blood cells (Guest, 1932). Daniel and Droz $(1960)$ reported that from $+3^{\circ} \mathrm{C}$. to $+6^{\circ} \mathrm{C}$. is the optimum range for the storage of bone-marrow and cultured cell strains.

Temperatures above $-10^{\circ}$ C. reduce storage time, and temperatures below $+2^{\circ}$ C. damage stored cells (Thistle, Gibbons, Cook, and Stewart, 1941).

There is as yet no evidence that corneal cells, and, in particular, the endothelial cells, should be kept at any other temperatures in short-term storage, and temperatures between $+2^{\circ} \mathrm{C}$. and $+8^{\circ} \mathrm{C}$. (with the optimum temperature of $+4^{\circ} \mathrm{C}$.) are generally accepted for the storage of fresh donor eyes for periods up to three days (Rycroft, 1959 ; Peña-Carrillo and Polack, 1964).

Whereas in box $A$ the specimen jars are completely surrounded by ice, in box B only a quarter of each specimen jar is in contact with the ice, the remaining three-quarters being enclosed by the insulating material. While the storage temperature of eyes in box A (and similar containers, such as a Dewar flask) will be very near the ice temperature and always below $+1^{\circ} \mathrm{C}$., that of the eyes in box $\mathrm{B}$ will, for all practical purposes, remain within the accepted range of temperatures.

The temperature of ice taken from domestic refrigerators varies, and the assumption that ice of a lower initial temperature will prolong the storage time is not only erroneous but dangerous, as cooling of the eyes to temperatures far below $0^{\circ}$ C. will take place.

The storage time for box A is short ; its mechanical strength and watertightness are both good, but really irrelevant. Foamed polystyrene is a good insulating material and in the thickness chosen for box B guarantees not only the necessary storage time but also mechanical strength. The weight and transportation cost of box B are low, and its price, about 6s. (box A costs about $£ 30$ ), has the particular advantage that it can be treated as "disposable" if the eyes are being sent to distant places.

\section{Summary}

A container for transporting donor eyes, made of foamed polystyrene, is described; and its performance compared with that of a metal box in current use.

The new polystyrene container maintains an interior temperature of between $+2.6^{\circ} \mathrm{C}$. and $+6^{\circ} \mathrm{C}$. for periods up to five days, whereas the metal container of earlier design is found to maintain the stored eyes below the accepted storage temperatures of between $+1^{\circ} \mathrm{C}$. and $-1.6^{\circ} \mathrm{C}$., and to retain a satisfactory above-zero temperature for insufficient periods.

A glass bell is described that will secure the eye within its jar and effectively prevent damage to the cornea during transport.

We are grateful for the co-operation of John Weiss and Son, London, who manufactured the glass bells. We would like to thank Baxter Laboratories Ltd., High Wycombe, for supplying the latexrubber caps. We are indebted to Jablo Group Sales Ltd., of Croydon, who advised us on the design of the box and supplied us with the many containers tested during the experiments. We also thank Dr. P. Hansell and his medical illustration department at Westminster Hospital Medical School for the illustrations, and both the secretary and nursing staff of the ophthalmic department for their help and co-operation. Finally, we are grateful to the Medical Research Council for personal grants to two of us (F. O. M. and P. O'N.) towards this research.

\section{REFERENCES}

Daniel, Ph. and Droz, B. (1960). Ann. Inst. Pasteur, 98, 416. Filatov (1922). Quoted by Smith, A. U. (1961) in Biological Effects of Freezing and Supercooling, D. 225. Arnold, London. Guest, G. M. (1932). f. clin. Invest., 11, 555.

Guest, G. M. (1932). 7. clin. Invest., 11, 555 .

Peña-Carrillo, J., and Polack, F. M. (1964). Arch. Ophthal., 72, 811.
Rycroft, B. W. (1959). British Surgical Practice: Surgical Progress, ycroft, B. W. (1959), British
p. 316. Butterworth, London. p. 316. Butterworth, Lo

Thistle, M. W., Gibbons, N. E., Cook, W. H., and Stewart, C. B. (1941). Canad. 7."Res., E., Section D, 19, 185.
Thrombophlebitis often occurs in women during pregnancy and the puerperium. During these periods there is a rise in the concentration of several different coagulation factors (Koller et al., 1952; Alexander et al., 1954). Oral contraceptive hormones simulate pregnancy to some extent and their administration has been associated with reports of the occurrence of thromboembolic episodes (Jordan, 1961; Zilkha, 1964). Egeberg and Owren (1963) suggested that one preparation, Enavid, caused a shortening of the cephalin time, a rise in antihaemophilic globulin (factor VIII), and a slight but significant increase in factor VII levels during the first and second weeks of therapy.

In the present investigation we have studied a large group of normal women taking a variety of oral contraceptive prepara- tions and have compared the results with those of a parallel group of normal female controls. In addition, we have studied the changes in coagulability which occurred in normal young females during moderate and severe physical exertion previously shown to shorten clotting-times and raise factor VIII levels in normal adults (Schneider and Zangari, 1951 ; Rizza, 1961). We also thought it important to include in the study the results obtained in patients with recent deep-vein thrombosis who were not on oral contraceptives and who presented during the period of this trial of oral contraceptives. This was to determine whether any changes in the treated women were similar to those which have been shown to occur in thrombosis (Poller, 1957). They were tested using the same technique and reagents.

* Research Technician, Withington Hospital, Manchester.

+ Consultant Haematologist, Withington Hospital, Manchester. 